\title{
COPROCESSAMENTO DE PNEUS USADOS E RESÍDUOS DE RERREFINO DE ÓLEOS LUBRIFICANTES USADOS EM FORNOS DE CLÍNQUER
}

\author{
R. J. SILVA ${ }^{1}$, M. N. BELATO ${ }^{1}$ e A. O. LOPES $^{1,2}$ \\ ${ }^{1}$ Universidade Federal de Itajubá, Instituto de Engenharia Mecânica \\ ${ }^{2}$ Centro Universitário do Sul de Minas \\ E-mail para contato: rogeriojs@unifei.edu.br
}

\begin{abstract}
RESUMO - A indústria cimenteira possui um alto consumo de energia térmica, e a utilização de resíduos como combustíveis alternativos e secundários, permite no coprocessamento, o aproveitamento do seu poder calorífico no processo produtivo. Com o aumento da produção e uso de veículos automotores, dois resíduos passaram a ter o seu tratamentos através do coprocessamento em fornos de clínquer de fábricas de cimento, os pneus usados e os resíduos do rerrefino de óleos lubrificantes. A prática do coprocessamento possui variações de acordo com a região, do tipo de processo de produtivo e da instalação de produção, para permitir uma alta eficiência de destruição térmica e baixa emissão de poluentes. Este trabalho analisa as restrições ambientais e de processo, que acabam por determinar os limites de alimentação destes resíduos nos fornos, quando o combustível principal é o coque de petróleo e coprocessamento ocorre em um forno rotativo com pré-calcinador com ar terciário e resfriador de grelhas.
\end{abstract}

\section{INTRODUÇÃO}

A indústria do cimento é caracterizada pelo alto consumo de energia, sendo que metade de todo o custo direto de produção de uma fábrica corresponde às despesas com combustíveis e energia elétrica (SNIC, 2012).

Os gastos de energia térmica referente à produção de cimento Portland estão diretamente ligados com o tipo de processo e tecnologia utilizada. Um consumo típico de uma fábica de cimento com forno rotativo dotado de uma torre de ciclones preaquecedores de seis estágios, o gasto de energia é em torno de 3000 a $3400 \mathrm{MJ} / \mathrm{t}$ clínquer. O menor consumo pode ser alcançado adotando o processo de via seca com o uso de pré-calcinador ligado a um forno rotativo de alta capacidade, com baixa umidade e boa capacidade de queima da farinha. Além do tipo de processo utilizado, a demanda do consumo específico de combustível de uma cimenteira é determinada considerando a composição química, mineralógica e a umidade das matérias-primas utilizadas, a capacidade de produção e a situação técnica da planta, as propriedades dos combustíveis e da mistura dos mesmos e a operação do forno rotativo (Belato, 2013).

O coque do petróleo é atualmente o combustível mais utilizado pela indústria do cimento no Brasil. Ele é originado dos processos de coqueamento, que processam os resíduos pesados derivados da destilação do petróleo, aumentando o rendimento global de uma refinaria em termos de produção de derivados leves e médios. O coque possui elevado poder calorífico 
associado com o baixo custo de aquisição. Existem dois tipos de coque: o coque verde e o coque calcinado. $\mathrm{O}$ coque de petróleo verde nacional possui um teor de enxofre de no máximo $1 \%$, já o coque de petróleo importado pode apresentar um alto teor de enxofre de cerca de 5\%. Ao ser queimado, o coque libera $\mathrm{SO}_{2}$, que irá reagir com diversos compostos presentes na matériaprima, incorporando-se ao clínquer. Atualmente no Brasil somente a Petrobrás é responsável pela sua produção. $\mathrm{O}$ coque verde pode ser subdividido em dois tipos principais: o esponja e o agulha (Petrobras, 2013).

A indústria do cimento é responsável por $2 \%$ do consumo de energia primária mundial (Nielsen, 2012). A fim de diminuir o consumo de combustíveis fósseis consumidos nesse processo, a indústria do cimento adotou a atividade de coprocessamento. Essa técnica consiste na queima, nos fornos rotativos de clínquer, de resíduos industriais e passivos ambientais que, devido ao seu poder calorífico possam ser utilizados como combustíveis. Os resíduos que são coprocessados são chamados de combustíveis alternativos ou secundários.

Os combustíveis fósseis vêm sendo substituídos com sucesso por diferentes tipos de resíduos industriais e passivos ambientais desde o inicio dos anos 70 pela Europa, Japão, EUA, Canadá e Austrália. A proporção do uso de combustíveis alternativos pela indústria do cimento Portland varia muito dependendo da região e do país. Dados de 2006, da Cement Sustainability Iniciative (CSI, 2006 apud WBCSD, 2009), mostram que os países da Europa substituem em $20 \%$ os combustíveis convencionais por alternativos. Já a América do Norte, o Japão, a Austrália e a Nova Zelândia apresentam uma taxa média de $11 \%$ de substituição. Por sua vez, os países da América Latina tem uma taxa de 10\%. A Ásia atingiu em 2006 apenas 6\% de uso de combustíveis alternativos.

Apesar da prática do coprocessamento variar de acordo com a região na qual a planta cimenteira se encontra, as características do processo de fabricação do cimento garantem a viabilidade do processo. Segundo a EIPPCB (Comissão Europeia de Prevenção e Controle da Poluição) (2009) apud UNEP (2010), as principais características do processo que garantem o completo consumo dos combustíveis alternativos são: a) a temperatura máxima de aproximadamente $2000^{\circ} \mathrm{C}$ (temperatura da chama) nos fornos rotativos; b) a retenção dos gases de aproximadamente 8 segundos em temperaturas acima de $1200^{\circ} \mathrm{C}$ nos fornos rotativos; c) a temperatura do material de aproximadamente $1450^{\circ} \mathrm{C}$ na zona de sínterização dos fornos rotativos; d) a oxidação dos gases da atmosfera nos fornos rotativos; e) o tempo de retenção do gás no sistema de queima secundário (pré-calcinador) de mais de 2 segundos em temperaturas acima de $850^{\circ} \mathrm{C}$. f) as temperaturas dos sólidos de $850^{\circ} \mathrm{C}$ no sistema de queima secundário e/ou no pré-calcinador; g) as condições de queima uniforme para flutuações de carga devido às altas temperaturas e tempos de retenção suficientemente longos; h) a destruição de poluentes orgânicos devido às altas temperaturas em tempos de retenção suficientemente longos; i) a absorção de componentes gasosos como o $\mathrm{HF}, \mathrm{HCl}$, e $\mathrm{SO}_{2}$ pelos reagentes alcalinos; j) a alta capacidade de retenção de partículas de metais pesados; k) o tempo de retenção curto dos gases de exaustão na faixa de temperatura conhecida por levar à formação de dibenzo-para-dioxinas policloradas (PCDD) e dos dibenzofuranos policlorados (PCDF); 1) a completa utilização das cinzas do combustível como componente do clínquer e, portanto, uma reciclagem de material e uma recuperação de energia simultaneamente; m) a não geração de produtos da queima dos resíduos devido a completa utilização do material na matriz do clínquer; n) incorporação química-mineralógica de metais pesados não-voláteis na matriz do clínquer. 
Portanto, pode-se concluir que as altas temperaturas e o longo tempo de residência nos fornos rotativos garantem a destruição dos compostos orgânicos. Além disso, o ambiente naturalmente alcalino do forno garante a absorção dos ácidos e óxidos e os produtos da queima dos combustíveis convencionais e alternativos são reciclados. Com essas características, a indústria cimenteira é ideal para se realizar a reciclagem energética dos resíduos industriais e passivos ambientais.

\section{COPROCESSAMENTO DE PNEUS}

Um dos resíduos mais utilizados como combustível alternativo é o pneu inservível. Em 2009, 180 mil toneladas de pneus foram coprocessados, o que corresponde a 36 milhões de unidades (SNIC, 2010). Uma das grandes vantagens da queima de pneus para a indústria do cimento é o seu poder calorífico, que normalmente se apresenta superior ao do carvão.

Os pneus inservíveis são considerados um dos grandes passivos ambientais da atualidade. Somente em 2013, foram produzidos 68,8 milhões de pneus, de acordo com as estatísticas da ANIP (2014). Da instalação da primeira fábrica até a primeira legislação sobre o descarte adequado de pneus, passaram-se 76 anos. Durante esse período, milhões de pneus foram descartados de forma inadequada em lixões, terrenos baldios, rios e lagos. Os dados desse passivo ambiental são incertos, podendo variar entre 100 e 900 milhões de pneus inservíveis dispostos de maneira incorreta no Brasil. Esses pneus representam um grave problema ambiental e também de saúde pública, pois é um criadouro de vetores de doenças como a dengue e a leptospirose (Nohara et al, 2005).

Devido à nova Lei $\mathrm{n}^{\mathrm{o}} 12.305$, de agosto de 2010, que se refere à Política Nacional de Resíduos Sólidos, espera-se que o descarte inadequado de pneus diminua já que os fabricantes se tornam responsáveis pela destinação final adequada dos pneus produzidos (Brasil, 2010).

A ANIP (Associação Nacional da Indústria de Pneumáticos), que engloba 10 das 17 empresas de pneus presentes no Brasil, possui um projeto de coleta e destinação adequada de pneus inservíveis que está em funcionamento desde 1999, chamado Reciclanip. O projeto consiste na instalação de pontos de coleta de pneus espalhados pelo país. Os pneus coletados têm o aço retirado e encaminhado para a indústria siderúrgica e a borracha triturada. Atualmente, a Reciclanip possui 743 pontos de coleta espalhados pelo Brasil. Desde 2010, quando foi criada a Política Nacional de Resíduos Sólidos, houve um aumento de $29 \%$ na quantidade de pontos de coleta instalados. Segundo a ANIP já foram coletados o equivalente a 270 milhões de pneus de passeio, durante todos esses anos de projeto (ANIP, 2013). A destinação de mais da metade dos pneus coletados pela Reciclanip são as fábricas de cimento, onde são queimados como combustível alternativo. Os pneus são encaminhados para as cimenteiras sem nenhum custo para as mesmas. O restante é destinado para a fabricação de manta asfáltica e asfalto-borracha, de pisos de quadra poliesportiva, artefatos de borracha, tapetes para automóveis ou solados de sapato (Reciclanip, 2013).

Devido a uma série de experiências bem sucedidas do uso do pneu no coprocessamento, a Alemanha adicionou o material a sua lista de materiais adequados para serem utilizados como combustíveis alternativos. Dependendo do local em que os pneus são queimados no forno rotativo, podem contribuir para a redução da emissão de óxido de nitrogênio (CEMBUREAU, 2009). 
Segundo Pipilikaki et al (2005), 88\% do pneu é composto de carbono e oxigênio, o que ocasiona sua rápida combustão e o poder calorífico relativamente alto (aproximadamente 31.400 $\mathrm{kJ} / \mathrm{kg}$ ). Esse alto poder calorífico do pneu faz dele um efetivo combustível alternativo, permitindo que a cada tonelada de pneu introduzida no forno rotativo, 1,25 toneladas de carvão possam ser reduzidas. A Tabela 1 apresenta a composição de várias amostras de pneus com os seus respectivos PCIs.

Tabela 1 - Composição química e PCI em kJ/kg de amostras de raspas de pneu

\begin{tabular}{|c|c|c|c|c|}
\hline \multirow{2}{*}{$\begin{array}{c}\text { Composição do } \\
\text { combustível }\end{array}$} & \multicolumn{4}{|c|}{ Raspas de Pneus } \\
\cline { 2 - 5 } & Amostra 1 & Amostra 2 & Amostra 3 & Amostra 4 \\
\hline Carbono & 72,30 & 75,90 & 77,60 & 79,00 \\
\hline Hidrogênio & 7,10 & 6,50 & 5,90 & 5,40 \\
\hline Enxofre & 1,54 & 2,00 & 1,10 & 1,47 \\
\hline Oxigênio & 5,00 & 0,50 & 0,30 & 1,80 \\
\hline Nitrogênio & 0,36 & 0,50 & 0,10 & 0,06 \\
\hline Umidade & 0,14 & 0,07 & 0,40 & 0,09 \\
\hline Cinzas & 13,70 & 14,60 & 15,00 & 12,20 \\
\hline Voláteis & 61,70 & 59,10 & 61,50 & 38,30 \\
\hline PCI (kJ/kg) & 33650 & 38970 & 35118 & 36055 \\
\hline
\end{tabular}

Fonte: Adaptado de Akkapeddi (2008).

Para a introdução de pneus inteiros, às vezes devem ser feitos ajustes no alimentador de combustíveis do pré-calcinador ou do próprio forno. No Brasil, onde a maioria das fábricas possui pré-aquecedor e pré-calcinador, é adotado um sistema de introdução de pneus como o da Figura 1. Nos sistemas de alimentação, os intervalos das aberturas das comportas ocorrem em função do tipo e do PCI do combustível que está sendo introduzido. Como os pneus necessitam de uma taxa de alimentação específica, um sistema de alimentação especial é necessário.

O controle da taxa de alimentação do pneu inteiro é considerado de extrema importância, pois o modo que ele é queimado no forno rotativo pode influenciar a emissão de CO nos gases de exaustão do forno (Signoretti, 2008). O alimentador de pneu é capaz de controlar a taxa de entrada dos pneus através de uma câmara à vácuo com comportas. Os pneus entram no précalcinador ou no forno com a abertura das comportas.

Com relação à composição química do pneu, a presença de zinco em sua composição pode contribuir negativamente na hidratação e no endurecimento do cimento. Portanto, substituição térmica de combustíveis tradicionais por pneus não podem ultrapassar valores entre 20-30\%, caso contrário poderá haver alterações negativas nas características físico-químicas do cimento.

Um componente químico do pneu que também deve ser cuidadosamente analisado é o enxofre. O pneu possui de $1 \%$ a $2 \%$ de enxofre em sua composição, conforme a Tabela 1. Essa quantidade é inferior à da maioria dos carvões utilizados nos fornos rotativos de clínquer, que irão conter quantidades inferiores a $1 \%$ de enxofre. Sabe-se que o carbonato de cálcio, a principal matéria-prima do cimento, reage com o gás sulfúrico contribuindo para o controle das emissões de enxofre nos fornos. Dados de diferentes fornos de clínquer relativos à emissão de enxofre demonstram uma queda, com o uso de pneus como combustível alternativo. 


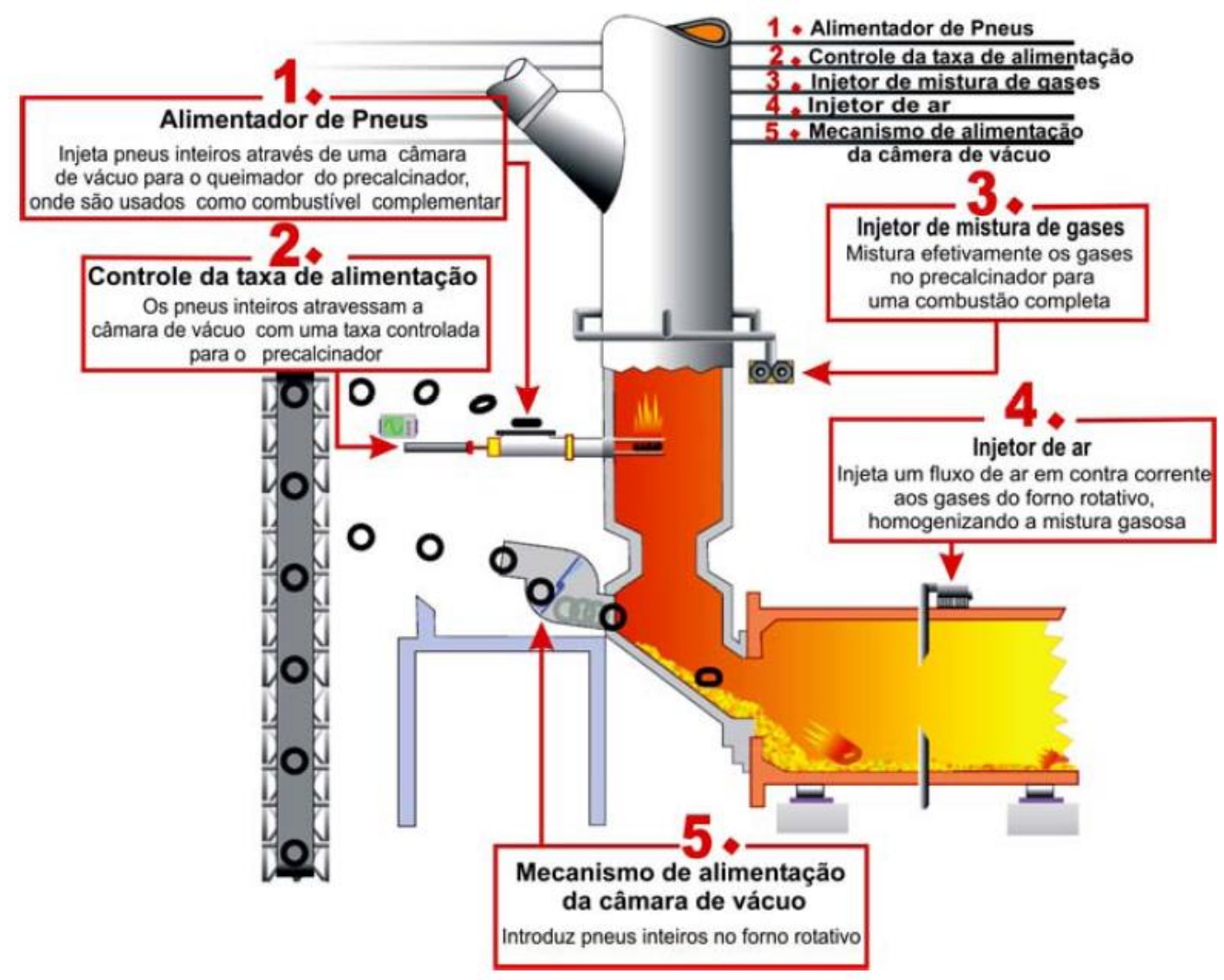

Figura 1 - Sistema de introdução de pneus inteiros em fornos com pré-aquecedor e précalcinador (Fonte: Signoretti, 2008)

Além da composição química, para analisar se é possível utilizar o pneu como combustível secundário é necessário o estudo dos subprodutos da queima do mesmo, pois podem se formar uma série de gases poluentes. Durante a queima, o nível de poluentes emitidos não deve ultrapassar aqueles previstos na legislação vigente. Nessa análise, os principais parâmetros que devem ser analisados são a temperatura a qual o resíduo será queimado e o tempo de residência do mesmo no forno rotativo ou no pré-calcinador, onde normalmente o pneu é introduzido. Os pneus, como todos os combustíveis alternativos, possuem uma porcentagem máxima que pode ser queimada no forno, levando em conta o poder calorífico e principalmente a restrição de emissão de poluentes. Muitos estudos indicam que a queima de pneus não deve ultrapassar $20 \%$ do total de calor requerido no processo, que é o que acontece na maioria das fábricas de cimento no Brasil (Paula, 2009).

\section{COPROCESSAMENTO DE RESÍDUOS DE ÓLEOS LUBRIFICANTES USADOS OU CONTAMINADOS}

Os óleos lubrificantes usados em motores automotivos e em vários processos industriais são formulados com alta carga de aditivação, buscando eficiência e maior durabilidade. São classificados em resíduo perigoso - classe I pela NBR10.004/2004, por apresentar em sua composição ácidos orgânicos, Hidrocarbonetos Polinucleares Aromáticos (HPAs), além de metais pesados como, por exemplo, cádmio, níquel, chumbo, mercúrio, cromo e cobre, todos considerados potencialmente carcinogênicos. Do consumo de lubrificantes tem-se a geração de 
resíduos, denominados óleos lubrificantes usados ou contaminados (Olucs) e conhecidos, na prática, por "óleo queimado". Esses resíduos têm alto grau de toxicidade à saúde humana e ao meio ambiente.

A logística reversa envolvendo óleos lubrificantes pós-consumo já é praticada no país desde 1963, quando a resolução $\mathrm{n}^{\circ}$. 6/63, do antigo Conselho Nacional do Petróleo, tornou obrigatória a sua coleta e destinação ao rerrefino. Os volumes vêm crescendo a cada ano juntamente com outros fatores do desenvolvimento recente do País. A Resolução CONAMA 362/2005 estabeleceu que todo o óleo lubrificante usado ou contaminado deverá ser recolhido, coletado e ter destinação final, de modo que não afete negativamente o meio ambiente e propicie a máxima recuperação dos constituintes nele contidos.

Ao final do processo de rerrefino o óleo lubrificante usado ou contaminado é extraído mais de $80 \%$ de óleo básico de petróleo substitutivo de óleos básicos importados, desonerando assim a importação deste insumo.

O processo de rerrefino consiste na remoção de contaminantes, produtos de degradação e aditivos dos óleos lubrificantes usados, conferindo as mesmas características de óleos básicos neutros, cujas características técnicas são iguais a do óleo de primeiro refino que é normalmente importado. O processo industrial conta com três tecnologias diferentes, a saber: a) Sistema Ácido Argila com "Termo Craqueamento" (nessa modalidade de tecnologia, predomina a obtenção de óleo básico neutro pesado); b) Sistema de Destilação a Flash ou evaporação pelicular (essa tecnologia propicia a obtenção predominante de óleo básico neutro leve e médio); c) Sistema por extração a solvente seletivo de propano (essa tecnologia propicia a obtenção de óleo básico neutro médio).

O processo amplamente utilizado no Brasil é o Sistema Ácido Argila, em desuso em diversos países, por razões econômicas, tecnológicas, produtivas e devido aos problemas causados pela geração de resíduos ácidos. Este processo apresenta, entretanto, baixo custo de manutenção e é capaz de tratar óleos usados de baixa qualidade e com contaminantes diversos. A baixa produtividade se deve ao processo ser em batelada, e possuir um arraste de óleo alto de cerca de $10 \%$ do volume. A geração de borra oleosa pelas indústrias de rerrefino instaladas no Brasil, é da ordem de aproximadamente 35.000 toneladas/mês, para um volume equivalente a 405.000.000 de litros de óleos lubrificantes usados coletados. A borra oleosa apresenta um PCI = $23000 \mathrm{~kJ} / \mathrm{kg}$. A Tabela 2 apresenta uma constituição típica da borra oleosa produzida, mostrando os metais que presentes em ppm (Gonçalves et al, 1999).

Tabela 2 - Metais Pesados Presentes na Borra Oleosa

\begin{tabular}{|c|c|c|c|c|c|c|c|c|c|c|c|c|}
\hline Elementos & Antimônio & Arsênio & Cobalto & Cádmio & Mercúrio & Tálio & Níquel & Selênio & Telúrio & Chumbo & Cianeto \\
\hline Símbolo & $\mathrm{Sb}$ & $\mathrm{As}$ & $\mathrm{Co}$ & $\mathrm{Cd}$ & $\mathrm{Hg}$ & $\mathrm{Ti}$ & $\mathrm{Ni}$ & $\mathrm{Se}$ & $\mathrm{Te}$ & $\mathrm{Pb}$ & $\mathrm{CN}$ \\
\hline Ppm & 25,1 & 0,34 & 5,3 & 1,27 & 0,06 & 0,25 & 13,11 & $\mathrm{Nd}$ & 3,17 & 163,82 & $\mathrm{Nd}$ \\
\hline Elementos & Cobre & \multicolumn{1}{|c|}{ Cromo } & Estanho & Flúor & \multicolumn{2}{|c|}{ Manganês } & \multicolumn{2}{|c|}{ Paládio } & Prata & Rhodio & Vanádio & Zinco \\
\hline Símbolo & $\mathrm{Cu}$ & $\mathrm{Cr}$ & $\mathrm{Sn}$ & $\mathrm{F}$ & $\mathrm{Mn}$ & $\mathrm{Pd}$ & $\mathrm{Ag}$ & $\mathrm{Rh}$ & $\mathrm{V}$ & $\mathrm{Zn}$ \\
\hline Ppm & 185,22 & 33,05 & 0,61 & 0,01 & $\mathrm{Nd}$ & $\mathrm{Nd}$ & $\mathrm{Nd}$ & $\mathrm{Nd}$ & 0,98 & 4520,02 \\
\hline
\end{tabular}




\section{LIMITES DE CONTROLE E DE EMISSÕES}

O coprocessamento de resíduos em fornos rotativos de fábricas de cimento deve atender aos limites máximos de emissão, constante na Resolução 264 do CONAMA, de 1999, com relação a um conjunto de metais, $\mathrm{HCl}, \mathrm{HF}, \mathrm{CO}$, MP e THC, expressos em base seca, conforme Tabela 3.

Tabela 3 - Limites Máximos de Emissão no Coprocessamento de Resíduos

\begin{tabular}{|c|c|}
\hline Poluentes & Limites Máximos de Emissão \\
\hline $\mathrm{HCl}$ & $1,8 \mathrm{~kg} / \mathrm{h}$ ou $99 \%$ de redução \\
\hline $\mathrm{HF}$ & $5 \mathrm{mg} / \mathrm{Nm} 3$ corrigido a $7 \%$ de $\mathrm{O} 2$ (base seca) \\
\hline $\mathrm{CO}^{*}$ & 100 ppmv corrigido a $7 \%$ de $\mathrm{O} 2$ (base seca) \\
\hline MP & $\begin{array}{l}70 \mathrm{mg} / \mathrm{Nm} 3 \text { farinha seca corrigido a } 11 \% \text { de } \mathrm{O} 2 \text { (base } \\
\text { seca) }\end{array}$ \\
\hline THC (expresso como propano) & 20 ppmv corrigido a $7 \%$ de $\mathrm{O} 2$ (base seca) \\
\hline Mercúrio $(\mathrm{Hg})$ & $0,05 \mathrm{mg} / \mathrm{Nm} 3$ corrigido a $7 \%$ de $\mathrm{O} 2$ (base seca) \\
\hline Chumbo $(\mathrm{Pb})$ & $0,35 \mathrm{mg} / \mathrm{Nm} 3$ corrigido a $7 \%$ de $\mathrm{O} 2$ (base seca) \\
\hline Cádmio (Cd) & $0,10 \mathrm{mg} / \mathrm{Nm} 3$ corrigido a $7 \%$ de $\mathrm{O} 2$ (base seca) \\
\hline Tálio (Tl) & $0,10 \mathrm{mg} / \mathrm{Nm} 3$ corrigido a $7 \%$ de $\mathrm{O} 2$ (base seca) \\
\hline$(\mathrm{As}+\mathrm{Be}+\mathrm{Co}+\mathrm{Ni}+\mathrm{Se}+\mathrm{Te})$ & $1,4 \mathrm{mg} / \mathrm{Nm} 3$ corrigido a $7 \%$ de $\mathrm{O} 2$ (base seca) \\
\hline $\begin{array}{l}(\mathrm{As}+\mathrm{Be}+\mathrm{Co}+\mathrm{Cr}+\mathrm{Cu}+\mathrm{Mn}+\mathrm{Ni}+\mathrm{Pb}+\mathrm{Sb} \\
+\mathrm{Se}+\mathrm{Sn}+\mathrm{Te}+\mathrm{Zn})\end{array}$ & 7,0 mg/Nm3 corrigido a 7\% de $\mathrm{O} 2$ (base seca) \\
\hline
\end{tabular}

\section{CONCLUSÕES}

A adoção de métodos eficientes de controle de emissão de poluentes pelas fábricas de cimento permite o uso de combustíveis e matérias-primas secundários no processo de fabricação do clínquer. Esse processo apresenta uma destinação final adequada para vários tipos de resíduos industriais e passivos ambientais gerados atualmente. Essa técnica de reciclagem energética aproveita o PCI dos resíduos através da sua queima gerando energia e simultaneamente a destruição térmica e o tratamento térmico dos resíduos, se bem realizada.

A Política Nacional de Resíduos Sólidos - Lei nº 12.305/2010, a DN COPAM nº 154/2010 (de Minas Gerais) e a Norma CETESB P4.263/03 (de São Paulo), proporcionam condições políticas e jurídicas ideais para o aumento da prática do coprocessamento pela indústria cimenteira no Brasil, especialmente no estado de Minas Gerais, o qual possui um dos maiores polos cimenteiros do país. Entretanto, os limites máximos de emissões de gases poluentes vigentes no Brasil são elevados comparados com o da legislação européia. Esses limites impostos não incentivam as indústrias de cimento nacionais a adotar medidas mais eficientes de controle das emissões de poluentes, como ocorre na Europa.

\section{AGRADECIMENTOS}

Os autores agradecem à FAPEMIG, CAPES, CNPq e PET-SESu/MEC, pelo apoio financeiro. 


\section{REFERÊNCIAS}

AKKAPEDDI, S. "Alternative Solid Fuels for the Production of Portland Cement". 2008. Dissertação (Mestrado) - Graduate Faculty, Auburn University, Auburn, 2008.

ANIP - Associação Nacional da Indústria de Pneumáticos. "Produção". Disponível em: < http://www.anip.com.br/index.php?cont=conteudo\&area=32\&titulo_pagina=Produ\%E7\%E3o $>$. Acesso em: Jan. de 2014.

Belato, M. N. Análise da Geração de Poluentes na Produção de Cimento Portland com o Coprocessamento de Resíduos Industriais. Dissertação de Mestrado, Programa de Pós-Graduação em Engenharia Mecânica, Universidade Federal de Itajubá, Itajubá-MG, 2013.

BRASIL, Lei $\mathrm{n}^{\circ}$ 12305, de 2 de agosto de 2010. "Institui a Política Nacional de Resíduos Sólidos". Disponível em: <http://www.planalto.gov.br/ccivil_03/_ato2007-2010/2010/lei/112305.htm>. Acesso em: Jan. de 2014.

CEMBUREAU - European Cement Association. "Sustainable Cement Production - Coprocessing of alternative fuels and raw materials in the European cement industry". [S.1.]: CEMBUREAU, 2009. Disponível em:< http://www.cembureau.be/sustainable-cement-production-coprocessing-alternativefuels-and-raw-materials-cement-industry>. Acesso em: 15 de Ago. de 2013.

GONÇALVES, J., SILVA, D. C., SILVA, R. J. Estudo da viabilização de co-processamento em fornos rotativos de clínquer da borra oleosa do processo de rerrefino de óleo lubrificante usado. Anais do $5^{\circ}$ Congresso Brasileiro de Cimento, Associação Brasileira de Cimento Portland, São Paulo-SP, 1999.

NOHARA, J. J., ACEVEDO, C. R., PIRES, B. C. C. P., CORSINO, R. M. "GS-40 - Resíduos sólidos: passivo ambiental e reciclagem de pneus". THESIS, São Paulo, ano I, v .3 , p. 21-57, $2^{\circ}$ Semestre, 2005.

PAULA, L. G. "Análise Termoeconômica do Processo de Produção de Cimento Portland com Coprocessamento de Misturas de Resíduos". Dissertação de Mestrado, Programa de Pós-Graduação em Engenharia Mecânica, Universidade Federal de Itajubá, Itajubá-MG, 2009.

PIPILIKAKI, P. et al. "Use of tire derived fuel in clinker burning". Cement\& Concrete Composites, Inglaterra, v. 27, p. 843-847, Março 2005.

RECICLANIP. "Reciclanip, o ciclo sustentável do pneu". Disponível em: <http://www. reciclanip.org.br/v3/>. Acesso em: Set. de 2013.

SIGNORETTI, V. T. "Controle das Emissões de $\mathrm{NO}_{\mathrm{X}}, \mathrm{SO}_{\mathrm{X}}$ e Metais Pesados Quando se Utilizam Combustíveis Alternativos e de Alto Teor de Enxofre na Indústria de Cimento". Tese de Doutorado, Programa de Pós-Graduação em Engenharia Mecânica, Universidade Federal de Itajubá, Itajubá, 2008.

SNIC - Sindicato Nacional da Indústria do Cimento. Press Kit 2011. [S.1.]: SNIC, 2011. Disponível em: <http://www.snic.org.br/>. Acesso em: 6 de Julho, 2012.

UNEP - United Environment Programme. Revised technical guidelines on environmentally sound management of used tyres and waste pneumatic tyres. Secretariat of the Basel Convention, UNEP,Geneva, Suiça, Maio, 59 p., 2010.

WBCSD - World Business Council for Sustainable Development. "Cement Technology Roadmap 2009: Carbon emissions reductions up to 2050". WBCSD, 2009. 36 p. Disponível em: <http://www.wbcsd.org/Plugins/DocSearch/details.asp?DocTypeId=25\&ObjectId=Mz Y3NDI>. Acesso em: 8 de Set. de 2010. 